\title{
A Meditation on the Post-digital and Post-internet Condition: Screen Culture, Digitalization, and Networked Art
} jan jagodzinski

\section{Post-Digital and Post-Internet Condition}

The rise of photography, the moving image, film, and advertising arts at the turn of the twentieth century reinstated a long-standing division that had developed during the Enlightenment with its revival of GrecoRoman classicism between the seven liberal arts (grammar, dialectics, rhetoric, arithmetic, geometry, music theory, and astronomy) and the mechanical arts (architecture, painting, sculpture, and agriculture), the familiar division between cognition, knowledge (mind) and skill, craft (body). These popular media forms were positioned against fine arts, with design straddling both domains. Toward the third quarter of the twentieth century this aesthetic division was still maintained between the 'arts' and 'media arts' as, not only did 'mechanization take command'

j. jagodzinski $(\bowtie)$

Department of Secondary Education, University of Alberta, Edmonton, AB, Canada

e-mail: jj3@ualberta.ca

(C) The Author(s) 2021

K. Tavin et al. (eds.), Post-Digital, Post-Internet Art and Education, Palgrave Studies in Educational Futures, https://doi.org/10.1007/978-3-030-73770-2_4 
as Sigfried Giedion wrote in 1948, but now computerization and digitalization took command. Media artists were the exponents of technical reproducibility as dictated by the limits of automation and the computer programs, just like the mechanical arts of the past, whereas the intellectual contribution of the creative act, the intuition and originality of the artist, was said to surpass the algorithmic forces of calculation, reason, and mechanical production. Machine and media generated production was still perceived as inferior (analogous to the 'craftsman' being inferior to the artist).

The shift toward a post-media condition, when art is produced with the aid of a digitalized technological device, began to constitute the core of media experience at the turn of the twenty-first century (Appich et al., 2013). Telematic and technogenic art (often referred to as bioart) began to be explored as both 'dry' and 'wet' media arts supported by digitalization and high-speed computerization enabled the collapse of art and science (Kac, 2007). Nature as culture and culture as nature blurred, best exemplified by biomimesis, biosensing, and biosynthetic design (Benyus, 1997). In brief, the 'use' of life as a medium (as visual media, as a 'science' medium, and as technological media) ushered in a postdigital and post-Internet world-view of materiality, which was forwarded alongside complex computation. Strictly speaking art \& design, and the historical tensions of the ampersand between them, became blurred if not disappeared. While traditional arts are still practiced, of course, their worth fades as DIY makerspaces that support STEM (Science, Technology, Engineering, Mathematics) projects infiltrate schools, libraries, museums, and galleries (Wiley \& Elam, 2018). The liberal arts of the Enlightenment, having morphed into the natural sciences, now infiltrate various technologies and all the mechanical arts.

In brief, the contemporary post-media condition shapes the post-digital and post-Internet condition where the media image dominates across screens and interfaces. Media convergence, where every mass media eventually emerges to a point of becoming one medium due to the proliferation of hybridized communication technologies is on its way (Jenkins, 2006). The cell phone, for instance, has become an entertainment center all on its own: television, music videos, Internet, geographical mapping, and so on are all available on this one device. The mediascape of the twenty-first century places us in a time that seems 'out-of-joint,' as in Philip K. Dick's (1959) dystopian novel. We, as a species, have entered 'the end times' wielding extraordinary technological achievements and a 
new-found arrogant consciousness summed up as a 'God-species' (Lynas, 2011 ) within the purview of an event horizon, our species extinction that a privileged few have helped shape: but to what ends?

Might we offer a radical thought at such a moment in time? Time that is now stretched out as an era; time that is stretched out even further as 'deep time'; the hysterical and paranoid time of Covid-19 global pandemic, yet another symptom of the time of fundamental planetary crisis of the Anthropocene. Time of eternal becoming, incomprehensible cosmic time; time that has no face; yet, as creatures of the Earth, a species of ape whose physiology and consciousness is shaped through and by the grammatization of technics (writing/media technologies) since Australopithecines first picked up eoliths, the first tools. We find ourselves now in a dromological condition (Virilio, 1986), pervaded by a 'dromospheric generation' (Colman, 2015). This generation of digi-children, immersed in digitalized technologies, are physiologically and psychologically shaped through play by three interconnecting components of media transmission: the transmission environment (TE), transmission manifestations (TM), and transmission perceptions (TP). Together, this forms an assemblage (agencement) of energy transmission-of informatics largely through sensations, affects, and percepts as peer-generated buzz occurs; a neurosynaptic chemical rush is produced.

Meaning is no longer the issue; that is to say, cognition takes a back seat, as the time-based material field provides the impulses and signals of transmission through the materialization of digital data. The impact of transmission differs given the platform environment (TE) that is harnessed. The force, intensity, and impetus of the energy that is produced depends in part by different algorithmic and perceptual data systems that the media platform uses, for instance, the sort of radiation of intensive light using intensive RGB additive color modeling, and so on.

With screen-based media platforms, image transmission is made possible through three modes of energy-potential (latent, static), kinetic (actual, movement), and cinematic [kinematic] (fluid, perception from the effects of movement, varying speeds on ocular, optical, or optoelectronic perception) (Virilio, 1998). Kinematic game platforms are made for the 'digivolution' of children of the dromospheric generation. They require a speed of play where digital dexterity, cognition, and abstraction of a narrative takes root, although narratives are not always required. Play is the platform activated most often through a handheld device that enables the flow and transference of energy through the body. It is through play 
that a territory is created, which then can be inhabited. This experience is an already programmed quantified algorithm; a game platform maps out potential and possible movements, actions, and pathways of console users as the game's ecology caters to a broad range of modalities. Paul Virilio (2000) develops the concept of 'chronopolitics' to grasp the logistics of channelling speed and managing time, so that a body is positioned and moved in space via affective knowledge.

Managing and manipulating bodies via such speed and time-based politics applies to any designed ecological environment, especially in urban planning where its territory is to be controlled. In game platforms, affective sequences of events are released at specific times, which sets up the desired 'relational product' between user and digital screen information. Power fields, set up by state institutions and private corporations, direct the synaptic and cognitive transmission of energy historicizing territorial movements by establishing habituated patters of self-time management (TM). Bodies are effectively colonized, the patterns broken only when an event (perturbation) occurs: accidents, protests, riots, but also militarism and health crisis like the current pandemic of 2020.

Since the turn of the twenty-first century, the dromospheric generation (or millennium generation), has set the stage for the future of digital work to meet the requirements of a global capitalist system, with virtual games as the exemplary techno-cultural form of Empire in their identity with the digital networks of production, communication, and deconstruction (Hardt \& Negri, 2000). The new 'secretaries' of the corporate world are the computer programmers and engineers. Machinic subjectivities arose via the military-industrial complex that had generated the computer and the Internet, with gaming becoming the testing ground to explore the enfoldment of the virtual and the actual, these two disjunctive realms perversely 'literalized' as philosophically developed by Gilles Deleuze and Félix Guattari (1987). The virtual as the digital, or on-screen world, is set apart to actual existential life, or 'IRL' ('in real life'), yet virtuality also opens up potentiality, the plurality of directions that the actual might take. It forwards the potential rather than the probable or possible.

While the technological and the ontologically virtual are distinct and not to be conflated, they become related through the practice of simulation. Computer simulation creates 'worlds,' potential or possible universes as to what might be. In relation to globalized control, such virtual simulation becomes vital for high-risk military, financial, and corporate institutions to retain their power of control. The gaming world provides 
the conditions to individuate a flexible subjectivity in this post-Fordist economy and labor that demands digital work, war, and the functioning of commodity markets. While gaming abets a machinic conscious necessary for global capitalism and industrial consumerism, it can also provide a critique of capitalism by amplifying its excesses. As Nick Dyer-Witheford and Greig de Peuter (2009) hedge their bets on three forms of creative dissident games: pirate, protest, and alternative Massively Multiplayer Online video games. As to their resistant effectivity, there isn't any obvious evidence in relation to the larger bleaker condition of game-use.

\section{Cybernetic Consciousness}

Virilio's 'dromoeconomic system' (Armitage \& Graham, 2001) extends and deepens our understanding of 'control societies' that Giles Deleuze (1992) developed by building on his friend Michel Foucault's exploration of disciplinarity and biopolitics. Deleuze was very aware of the way second-generation cybernetics enabled the modulation of open and dynamic systems whereby power seemed decentralized, absent, yet in 'play.' Virilio and Bernard Stiegler (as discussed below), and theorists like Levi Bryant (2011) have engaged with third and fourth order cybernetics. Simply put, first order cybernetic systems dealt with allopoietic machines that are used for a set purpose, a clear telos. They cannot produce their own components and are simply observed; second order cybernetics deals with autopoietic machines, the self-organization of living biological systems (Maturana \& Francisco Valera, 2012). They produce their own components. They are teleonomical in the sense that their purpose and organization is ecological; they encephalize their environment and are able to modify it to certain extent through causal feedback. In this sense they are 'self-observing systems.' Third order cybernetic understanding combines the understanding of first order (as culture of machines) and the second (as the nature living machines). Generally speaking, a networked system redirects itself as a particular element within it, or any combination of elements, begins to modify and redistribute the system.

The awkward term, 'natureculture entanglement' is the result where our species recognizes how modifications of nature are modifications of culture, both physiologically, neurologically, psychologically, and so forth; in brief, the degree and intensification of encephalization matters. Third order cybernetic systems are heteropoietic; there is a wide variation. Further, they are both teleological and teleonomic, meaning there is an 
exchange between singular autonomous elements of a system in the environment. Fourth order cybernetic systems build on and embed the other three orders. The term 'assemblage' [agencement] is more suitable here as initially developed by Deleuze and Guattari (1987), where desire, as a form of energy, circulates keeping the system in place at a metastable level. Modifications of change happen via events (perturbations), which happen at extremes states of disequilibrium when a phase change takes place. The system redirects itself: the observer and the observing system transform one another as 'information' is generated. Contingency and complex causalities (what Deleuze (1994) called 'dark precursors') deterritorialize and redistribute the system's elements as it transformations itself.

Fourth order complex dynamic systems are governed by entropynegentropy dynamic where the inside and outside, intensive and extensive forces, endo-relations and exo-relations as dualities are in constant states of flux or 'becoming.' A both-and logic prevails referred to as a paradoxical 'disjunctive synthesis.' This suggests an impossible and unbridgeable gap between thinking (epistemology) and being (ontology, the Real). Holarchy best defines such a system, as does a holographic projection where the connection and relations between elements as holons take place, a holon being both part and whole. Indeed, the part contains the whole. Such holarchic systems are no longer hierarchical, but more quantum-like, in this sense the term 'flat ontology' appears appropriate. The relationships between holons at different levels are no longer above and below, as charted by representational imagery; rather both 'in and out,' 'up and down,' 'left and right,' and 'inside and outside.' Holons are inter and intra-related as in a holograph where any one part contains the whole simultaneously. This is not unlike fractal dimensions of Euclidean geometrical space, which present expanding or unfolding symmetries. The topological dimensions of their becoming seem to generate infinite scales. We have arrived at this point at speculative realist philosophies, especially quantum that informs post-digital and post-Internet concerns. This development will not be pursued due to space restrictions.

\section{Where to Now?}

Virilio's (1994) 'logic of the image' in advanced control societies is rather bleak. It is an advanced form of 'accelerated aesthetics' best captured in this overview from The Vision Machine. He writes: 
The age of the image's formal logic was the age of painting, engraving and etching, architecture; it ended with the eighteenth century. The age of dialectic logic is the age of photography and film, or if you like, the frame of the nineteenth century. The age of paradoxical logic begins with the invention of video recording, holography and computer graphics [digital imagery] ... as though, at the close of the twentieth century, the end of modernity were itself marked by the end of a logic of public representation. (1994, p. 63, original emphasis)

Virilio's technological determinism via vision machines is highly problematic as the material space is said to be replaced by speed's space as 'no-place'- the immediacy of real or actual time. The collapse of the vanishing point of Western technological development; that is, the collapse of both 'distance' and 'horizon' presents a 'squared horizon' in Virilio's terms (2005). Screen reality becomes pixelated and rests on the 'surface.' The pixel, as a 'micro-element' of the image, a point without dimension, says Virilio (1991). It flattens the image literally and symbolically into 'discontinuous grain.' It does away with the human experiences of space as it enables the digital image to be zoomed into or out of. Vision becomes flattened at the macro and micro levels: the zoom-in being too small for the human eye to see, the zoom-out presenting vistas that are too large to be contained in the field of vision. Digital imagery homogenizes everything through indifference to what it 'captures.' Translating material objects into digitalized images is said to destroy the phenomenological depth of the thing. Bodies are obliterated in a phobia of corporeality.

The screen is theorized as an absolute surface creating the effect of infinite depth, as such this is a 'negative horizon' as distance is collapsed into absolute proximity. The effect of this, says Virilio, is that the subject is caught up in a solipsistic space, held by the prison of a reflective surface where attention is captured by its illuminated aesthetic and its ability to fascinate. The viewer is transformed into a virtual 'tech-no-body' shaped by a negative abyss, a bottomless surface that engulfs the dystopia of the twenty-first century (Featherstone, 2015). To be fair, it might be also said that Virilio's (2011) concepts of 'anti-form' and 'divergence' are ways to critique, resist, innovate and reverse the perception of figure-ground through a 'tetradic form.' By focusing on the spaces of between, Virilio enhances the awareness of ground and interval; the figure's orientation becomes obsolescent, while his 'staticism' retrieves alternative dynamic 
and vitalist perspectives that are then pushed to the extreme. This reverses the world into a rabbit-hole view. So, while Virilio does present a form of technological determinism, his approach to media ecology can be thought as being paradoxically the opposite (Zhang, 2013).

In the context of a post-digital and post-Internet art, the screen becomes the primary object of contention and concern, not only for the future of youth but also for the constant capture of affect and emotion for marketing. Desire is intensified into a 'drive' (Trieb) to energize the capitalist machine by having everything be present to hand (like in Amazon's prime delivery system). One wonders if this general claim of the 'screen' is applicable to Internet artists such as Pamela Rozenkranz, Oliver Laric, Juliana Huxtable, and Ryan Trecartin. ${ }^{1}$ They address the way in which the Internet has changed communication through social media dramatically influencing their art: the proliferation of multiple individual narratives that unfold simultaneously, shifting genders and identities, over-the-top consumerism, and the proliferation of communicative exchanges among youth. They also do not limit their art to the Internet, but draw on the changes in perception brought on by the particularity of its technology. In Trecartin's case, his work is obviously 'overcommunicative': messages from dramatized exaggerated 'selves' proliferate in his videos, like a stream of solipsistic melodramas consisting of a constant flux of intensified images spewing existential angst. The question remains whether this aesthetic and affective style simply caters to and targets desire (Trieb) of a millennial generation, as he himself seems to confirm: 'My satisfaction comesat least in part-from giving people what they want' (qtd. in Tomkins, 2014); or, is his overrepresentation of Internet social reality via the video screen a form of satirical criticism and hyperbolic intervention? The paradox lingers.

The Institute of Contemporary Art (ICA), Boston held an exhibition in 2018 curated by Eva Respini entitled Art in the Age of the Internet, 1989 to Today, which featured the millennial artists mentioned. The exhibition was divided into five sections, categories that are telling of the Internet's influence on art: Networks and Circulation, Hybrid Bodies, Virtual Worlds, States of Surveillance, and Performing the Self. Each of these areas can be thought of generating its own aesthetic and politics of desire. Juliana Huxtable can certainly be highlighted here in relation to issues of representation in the 'Performing the Self' section. As a transwoman, her portraits and performances are meant to 
question the usual sex-gender divide, claiming to be a cyber-cunt-blackwitch-Nuwaubian princess. An exploration of various digitalized portraits appears in the exhibition that scramble these signifiers into various hybrids of her 'self,' not unlike Orlan's somewhat infamous series of selfhybridizations that borrow physical features from other cultures. More pointedly, in collaboration with Huxtable's support and desire, is the juxtaposition of Frank Benson's hyper-realistic bronze sculpture: Juliana (2014-2016), which was constructed with the aid of 3-D printing technology. The sculpture is finished with a metallic autobody green paint. This gives the 'sculptural-portrait' a digital machine-like finish to provide the look of an 'ideal pose' that traces classical historical elements of nudes. Not atypical for many post-digital artists, Benson alludes to Deleuze's (1992) early concept of simulacra where the distinction between original and copy as formulated by Plato's idealism no longer applies. The 'ideal' bronze of Juliana is but one actualization of a series, beginning with her scanned body as a 3-D coded virtual image that is then actualized into 3-D print form, which is then further rendered into a 'traditional' bronze sculpture (see Respini, 2018).

The realization of this politicization of affect theory has (finally) gripped the academy in the past decade or so (Massumi, 2015). Lacan's (1995) gaze-look paradox is taken a step further in this realm of hyperspecularization. Bernard Stiegler (2010a) maintains that consumerist societies are marred by decadence, disaffection, and drive, resulting in an 'addictogenic subject.' Here we can point to the proliferation of 'apocalyptic memes' that flood the Internet (Konior, 2019), and the alt-right as the most visible dealer of 'fake-news' tweets and memes (Owens, 2019). Memes in the post-Internet constitute one of the easiest artforms to manipulate and modulate the structures of feeling. For Stiegler, like Virilio (see Featherstone, 2010), a death drive pervades the screens that offer perpetual satisfaction of escape, which can only lead to their complete closure as eternal peace. It would appear that the BBC's television series Black Mirror is a good accounting of such a black screen Virilio and Stiegler have in mind where a form of disorientation takes place that leads to immobility rather than enabling place and identity in terms of transindividuation that Stiegler (2010b) (via Gilbert Simondon) stresses. Transindividuation refers to the absolute necessity of forming relationships that are of some depth where community care can take form. 
Stiegler $(2014,2015,2018)$ mobilizes the concept of pharmacology and organology in order to rethink the Anthropocene as the 'Neganthropocene' in this post-Internet and post-digital condition, which is characterized by him as 'symbolic misery.' Algorithmic governmentality and the prosumer mentality of 'clairvoyance societies' have been the next steps of intensification of cybernetic control societies (Neyrat, 2018). We are 'proletarianized' by automation in Stiegler's view, the loss of the vital knowledge how to live and act well. The pharmakon, effectively put to use by Jacques Derrida (1981) (Stiegler's teacher) as a way of articulating the production of différance when applied to wiring as being both a poison and cure is extended to the ambiguity of all techné. In what he calls a 'general organology,' as first derived from musicology, refers to and calls for a paradigm shift that accounts for all technical instruments and their effects on the human being, and their social organization for the transformation of the humanities, to reverse the entropy of human extinction. The toxic pharmakon of the 'short-circuited technologies' of screen cultures require new digital tools for human transindividuation processes to encourage care within the malaise of the Anthropocene, to wit referred to as the Neganthropocene given that negentropic energy is required for this transformative reversal.

Drawing on the Gilbert Simondon's insightful and ground-breaking history of techno-human relations, Bernard Stiegler (1998) defined technics as organized inorganic matter. As such technics refers both to the history of fabricated objects (as design) that require epistemé (cognition, knowledge), and to the domain of techné; that is to the techniques, processes, and practice involved in making technology (as art, craft, skill). Stiegler's presents a version of the interrelations between the biological, social, and the technological system as the history of epiphylogenesis (the technical-biological evolution). Organology is the process of exchange and mutual connection that takes place between tools (technics) and human beings in a sociological institutional environment that results in the formation of subjective consciousness (individuation). Organology (from the Greek, organon for tool) studies the psychic, artificial, and social tools that are constantly evolving and affecting each other. Technics in this understanding is the coalescence of art \& design, not as separate but related spheres as has been the dominant paradigm of Western thought ever since the Aristotelean division of labor was taken up by the Enlightenment: between mind, spirit (knowledge of the seven liberal arts as sciences), and body (craftsmen, laborers, material). It is the recognition 
of the intra-relations of nature and culture that have always been in play in our species evolution and accelerated since the industrial revolution of the nineteenth century to evolve into, what Michel Serres (Watkin, 2020) coined as 'exodarwinism'. This term should be understood by Marshall McLuhan's (and Edmund Carpenter, 1956) claim that: 'Each new technology is the reprogramming of sensory life.'

The relationship of our sense organs to each other, as well as the relationship of the sense organs to the environment, is constantly reprogrammed by new technologies and, consequently, our sensory life rewritten. Such a position by Serres is no different from Stiegler, they are compatible. A 'general organology' is the same idea that with every different set of (technical) organs comes into play a whole new set of psycho-somatic organs and social organization. It should be understood that technics (the domain of fabricated objects and the techniques and processes involved in their making) are constitutive of physiological and psychic changes of our species-becoming on all levels (from retention to anticipation, from cultural history to genetics); it is not a question of separating technology from a thinking and living body, as simply a prosthetic, rather this position recognizes that inter and interactions that occur between body, flesh, gesture, mind, and exo-technologies are mutually constitutive. Technics as a supplement (Derrida's 'always already' or 'already there') has always modified the species. To riff on Bruno Latour: We have always been cyborgs via gramatization as the interplay between gramme and gestures (in the widest sense of bodily motility) historically change.

Stiegler makes the point that the digital gramme has datafied existence to the point of a general consumer proletarianization, an intensification since nineteenth-century industrialism via the further capturing of tertiary retention (technical memory) through the archiving of data. All such 'writing' technologies are subject to a pharmacology; that is, their contextualization either prohibit or forward an existential openness. One of the advantages for thinking with the gramme is to differentiate the specific affordances of media platforms to begin to grasp what is it that is 'new.' In what ways are new technologies 'performative' in their affects and effects? Stiegler's general call for a transformative change addresses the need for a new 'natural contract' as Michel Serres (1995) once put it. Educators who have taken Stiegler earnestly to heart, seem to be all over the place as to precisely what such a renewed contract might be (Educational Philosophy and Theory, 2020). I end this meditation by turning my 
attention to selfies as the paradigmatic images of post-digital and postInternet cultures, and then reviewing three networked art installations that exemplify one aspect of the networked digital image in relation to the concerns raised by Virilio and Stiegler.

\section{Networked Digital Images}

The ubiquity of networked screen images in our digital age have challenged artists in unprecedented ways: how to engage with the Internet, the glance of the image, and the technology of the digital. What constitutes 'art' in Web 2.0 where the various platforms of capitalism are operable? Can they be intervened in a way that would increase our wellbeing as Stiegler desires? Is the dystopia of destructive memes, fake news accusations, and the traps of neurological research to grab prosumer attention a state of affairs that will only intensify, as Neyrat (2018) argues, when he speaks of clairvoyant societies that already predict the future via big data, explored by any number of sci-fi films and television series from Westworld to DEVS. Web 3.0 is just around the corner, or perhaps it has already arrived, and we just don't know it yet.

Historically, Daniel Rubinstein and Katerina Sluis (2008) are generally credited with the early mapping and use of the digital snapshots posted on the Internet, the mass amateurization of snapshots circulated throughout the net via photo-sharing and social networking. These sites attest to the transparency and visibility of the world-for-us; photos as placeholders for memories, celebratory documentations, sightseeing trips, in short, the rituals of everyday life, the various clichés of 'living.' The number of digitalized images that are uploaded onto servers each day can only be approximated: in 2019 there were 1.59 billion daily users of Facebook posting stories; 350 million photos are uploaded daily on its site; while on average 95 million images are uploaded on Instagram. A host of other online sites (Snapchat, Flickr, SmugMug, Buzznet, Zoto, Tumblr) add to this staggering total. The strategy of tagging (adding text) called 'folksonomy' on sites like Flickr encourages archiving and prevents photos from disappearing from view (Smith \& Lefley, 2016). What is new to this extraordinary phenomenon has been the generation of metadata. A networked file has geographical coordinates of the place of shooting, it also allows the image to escape its original context enabling images to be remixed and remapped as mashups opening the door for hackers and reprogrammers via algorithms to play with images in new ways. Gone 
are narrative and mnemonic values, indexicality as well as any status of a posted image being a precious object. Transmission-orientated, screenbased experience of images (especially photographs) leads to a stream of data where such images and their significances are in a state of constant flux.

Communicative capitalism (Dean, 2009) or platform capitalism works much the same way through the proliferation of videos, memes, emojis, photos and the like, but with more force as a 'second visuality'. What matters is whether an image is able to be repeated, or excites imitation, and whether it can circulate from one context to another. Production and reproduction become inseparable. The power to repeat and multiply gives it force, a triumph over meaning where affect and emotion are mobilized. Media studies have finally understood this phenomenon that form, content, and meaning are never fixed, but complexly related in relation to the user-spectator-participant-console user. This results in collective bubbles in the Internet (fan groups, hate groups, alt-right groups, leftgroups, and so on). Digital images are not meant to be looked at; the less unique and banal, the better, as this is a scan aesthetic, meant to be repeated and imitated, reiterated, glanced at to share and scroll on or down. Deleuze's notion of the 'dividual' emerges in the commonality and reproducibility of the selfie. The weird, odd, out of bounds, and unusual is gathered up, captured, and presented as yet another social media bubble to enter. 'A Life' has disappeared in communicative capitalism. I use Deleuze's (2001) term 'A Life' to point to the free flow of creative energy $(Z o \ddot{e})$, energy that has not been captured by capitalist means (bios).

As Deleuze and Guattari (1994) note: 'We do not lack communication. On the contrary, we have too much of it. We lack creation' (p. 108). This seems to be the worrying consensus of many Deleuzians when it comes to the 'monadology' of the selfies (Ross, 2015; Vignola, 2015). The selfie has become a critical tool to use in political campaigns. Anirban Baishya (2015), for example, explores how the selfie of Narendra Modi was successfully used to help win his election as the prime minister of India. The alt-right political party, Bharatiya Janata Party (BJP), successfully mobilized a twitter propaganda campaign posing selfies of Modi with young and old people alike that swayed the public; it became cool to have such political leaders 'levelled' as it were, as part of public (like Trump eating hamburgers). There are artists, of course, who try to disrupt the 
'selfie' assemblage. STEFDIES (stefdies.com) claims that her performative pieces are 'anti-selfies,' a rethinking of photography by capturing and staging moments of her 'death,' maintaining that her photographs are by chance (rather than being staged), yet they demand her total commitment for 'the' moment of capture. Hence, there are many failures at capturing her 'time', from a $\mathbf{1 0 0 0}$ there are only a few hundred that are 'useable.' They can be thought of singularities that make the viewer think about the context of the situation where her 'dead' body lies.

There are, of course, no easy pushbacks to communicative capitalism. The harvesting of data from the various platforms has intensified. Let me examine three artists who present networked images in art exhibitions, generating a strange resistance to evoke forces of the unthought, providing the formation of new relationships to images. Erik Kessels' Photography in Abundance (24 h in Photos) (2011) installation exhibition does a very strange thing: it quantifies flow, stills time, and seems to evacuate the very desire, perhaps drive in the Lacan-Stieglerian sense is more adequate; that is to say, the circuits of satisfaction as forces of intensity that sustain enjoyment (jouissance) of the networked images are ruined. The repetitive circuits that sustain the social bubbles are cut, evacuated, rendered in a form that seems to be a wasteland marked by heaps of trash. Kessels, an artist, designer and curator, downloaded a million photos that were uploaded and publicly accessible to Flickr over a $24 \mathrm{~h}$. period. The images were saved on a hard drive via an algorithmic program; then they were printed on paper and spread on the floor of the exhibition space (Amsterdam's Fotografiemuseum-FOAM, 10th anniversary show entitled, What's Next?). The million digital images were then transformed into physical prints, heaped up in piles, the resulting scale was a shock to the eyes. The equality of the image-mass of photos speaks to the 'commonism of images' managed by platform capitalism for profit ends that parasites on the dreams and desire of those who posted their image-texts, and took their selfies. It is the organizational structure of these images, witnessing the affectivity of 'A Life' that has now but vanished; as if the spirit that drives that structure has left, no longer traceable, leaving only waste behind.

The lack of entropic order of these images, the piles upon piles, deconstructs the exhibition space: there is no selection of works, only a presentation of everything; no origins and no framed prints only cheap inkjet prints and colored copies; no barriers keeping spectators away. Rather, they were encouraged to walk over the heaps and take images 
away, seemingly an empty gesture. This was followed by a reversal. Kessels' One Image exhibition in 2016 appeared in a gallery space in Wroclaw, Poland. A black and white photograph of a little girl, Kessels' sister, who died after being hit by a car at the age of nine was singularly left hanging. It was the last image of her ever taken. He also reproduced the same image and put it on posters, scaffolding and billboards around the city, as well as in newspaper ad spaces - perhaps the obituary section being the most poignant. Her memory as a singularity-A Life-was heightened by escaping the networked Internet image.

Pic-me by Marc Lee (Version 1: 2014; Version 2: 2016) works with Instagram images and the specificities of Google Earth to show precisely where a recently uploaded photo was taken. An algorithm searches new posts on Instagram to identify images that have the following three features that are then filtered and chosen: hashtagged with \#me, publicly visible and geotagged. So, every time an Instagram photo is uploaded, meeting these three requirements, the post appears as a speech bubble that points to the location of the transmitter. Google Earth becomes a spinning globe, and we approach the post and zoom into the closest proximity on the globe. Satellite imagery with aerial views, street views, and 3-D mapping of cities depicts the surface features and presents a holistic flow for the spectator. If one goes to: https://www.youtube. com/watch?v=PdubyhvetQw the installation can be experienced. This is a never-ending work as new posts are constantly feeding the algorithm and appear almost as real time. The installation lays bare communication capitalism as the personal data are tracked and traced on the Internet. On the one hand these are anonymous posts, yet they are easily identifiable, surveyable, and localizable. It is well known that these personal and often emotional posts are collected by commercial enterprises, research institutions, governments and then stored in databases. Above all, like Kessels' work, this seeming endless series of short posts, which one can watch as the globe spins, leaves one with a feeling of emptiness, as well as fascination. No one post remains long enough to go beyond the superficiality of surveillance, experiencing the fleetingness of lived-life. No commitment seems to occur on the part of the spectator because of the speed of the procession. These posts are like moving images that are scattered around the globe, not to be identified with but, in one sense, mourned for their very anonymity as A Life (Zö̈) seems to be sealed, packaged as bios. Marc Lees installation speaks to Virilio's concerns as the speed of looking is a factor that seems to empty any needed distance as there is no touch. 
The last installation, is an interactive kinetic sculpture, A Truly Magic Moment (2016) by Adam Basanta. It is available for viewing on https:// vimeo.com/172547512. The networked video image communication consists of two iPhone cameras mounted on two robotic arms directly opposite one another; they are set in motion in a circular spin when two viewer-participants call in and are able to see one another via the iPhone screens. The sculpture then starts spinning, presenting them with 'a truly magical moment' of intimacy and a potential romantic relationship. Clearly this is a parody of what may happen online when two people chat, meet, and fall for one another, a contingent event. A counter records all the 'magical moments' that have taken place via the networked assemblage that consists of the technological apparatuses, both inside and outside the gallery space (satellite, two iPhones, the physical sculpture, and so on). Authenticity is being questioned, yet perhaps 'true love' is possible? An event of two people meeting and falling in a relationship is not uncommon online. It is the event of that moment, which is where one may say a folded time-space has happened. But the artifice of the sculpture also points to the sheer folly that this can ever happen, its physical swirling poking fun at the unlikelihood of such a 'magical' moment.

To conclude: there are many aspects of a post-digital and post-Internet technological condition, many of which I have not covered. There is one, however, I wish to leave on, and that is the entanglement of analog and the digital. It is a point I have not stressed, as there are art movements which appear, at first glance, to favor analog technologies at the expense of the digital: analogue photography, layering analog and digital images in Instagram, the use of phonograms and cassettes, the turn to knitting (in classrooms during presentations!), and, perhaps the most obvious and interesting: steampunk. One finds artworks where traditional art is 'entangled' with digital aspects; an entire 'craft' culture that comes across in some makerspaces seems to convincingly usher in an 'analog renaissance,' or some sort of analog nostalgia.

But, there is no going 'back.' All these initiatives involve forms of digitality of one sort or another; this is especially true with steampunk, which delights in its digital tactility via its recall of the past. Some maintain that these movements are mere forms of 'remediation' (Bolter and Richard Grusin, 2000), whereas others see this as too limited: the term post-digital needs to be replaced and recognized as transdigital-as technologies of transformative practices; a recognition that such transdigital encounters and practices present the very materiality of technologies with their own 
array of affective relationalities (Sundén, 2003). Analog media intensifies the materiality of the digital, and isn't about to go away. This trajectory, as many have pointed out, leads to more and more intelligent AI. The question will always remain open: to what ends? For our well-being or are detriment? The pharmakon, as remedy, poison and scapegoat awaits.

\section{Note}

1. I would like to thank Gila Kolb for making me aware of these four artists.

\section{REFERENCES}

Appich, C., Slater, J. B., Iles, A., \& Schultz, O. L. (Eds.). (2013). Provocative alloys: A post-media anthology. Post-Media Lab \& Mute Books.

Armitage, J., \& Graham, P. (2001). Dromoeconomics: Towards a political economy of speed. Parallax, 7(1), 111-123.

Baishya, A. (2015). \#NaMo: The political work of the selfie in the 2014 Indian general elections. International Journal of Communication, 9, 1686-1700.

Benyus. J. (1997). Biomimicry: Innovation inspired by nature. William Morrow.

Bolter, J., \& Richard Grusin, R. (2000). Remediation: Understanding new media. MIT Press.

Bryant, L. R. (2011). The democracy of objects. Ann Arbor: Open Humanities Press.

Carpenter, E., \& McLuhan, M. (1956). The new language. Chicago Review, $10(1), 46-52$.

Colman, F. J. (2015). Dromospheric generation: The things that we have learned are no longer enough. Cultural Politics, 11(2), 246-259.

Dean, J. (2009). Democracy and other neoliberal fantasies. Duke University Press.

Deleuze, G. (1992). Postscript on the societies of control. October, 59, 3-7.

Deleuze, G. (1994). Difference and repetition (P. Patton, Trans.). Columbia University Press.

Deleuze, G. (2001). Pure immanence: Essays on life (A. Boyman, Trans.). New York: Zone Books.

Deleuze, G., \& Guattari, F. (1987). A thousand plateaus: Capitalism and schizophrenia, vol, 2. (B. Massumi, Trans). University of Minnesota Press.

Deleuze, G., \& Guattari, F. (1994). What is philosophy? (H. Tomlinson \& G. Burchell, Trans.). Columbia University Press.

Derrida, J. (1981). Plato's pharmacy. In B. Johnson (Ed. \& Trans.), Dissemination (pp. 61-171). The Athlone Press.

Dick, P. K. (1959). Time out of joint. J.B. Lippincott. 
Dyer-Witherford, N., \& de Peuter, G. (2009). Games of empire: Global capitalism and video games. University of Minnesota Press.

Educational Philosophy and Theory. (2020). Stiegler as philosopher of education, $52(4)$.

Featherstone, M. (2010, September 16). Virillio's Apocalypticism. Ctheory. Online.

Featherstone, M. (2015). The negative abyss: Surface, depth, and violence in Virilio and Stiegler. Cultural Politics, 11(2), 210-221.

Giedion, S. (1948). Mechanization takes command: A contribution to anonymous history. University Oxford Press.

Hardt, M., \& Negri, A. (2000). Empire. Harvard University Press.

Jenkins, H. (2006). Convergence culture: Where old and new media collide. New York University Press.

Kac, E. (Ed.). (2007). Signs of life: Bio art and beyond. MIT.

Konior, B. M. (2019). Apocalypse memes for the Anthropocene God: Mediating crisis and the memetic body politic. In D. Bristow \& A. Bown, (Eds.), Post memes: Seizing the memes of production (pp. 45-76). Punctum Books.

Lacan, J. (1995). Reading seminar XI: Lacan's four fundamental concepts of psychoanalysis (R. Feldstein, B. Fink, \& M. Jaanus, Eds.). SUNY.

Lynas. M. (2011). The God species: Saving the planet in the age of the humans. National Geographic.

Massumi, B. (2015). The politics of affect. Polity Press.

Maturana, H., \& Francisco Valera, F. (2012). Autopoiesis and cognition: The realization of the living. D. Reidel Publishing Company.

Neyrat, F. (2018). Occupying the future: Time and politics in the era of clairvoyance societies. In S. Witzgall \& K. Stakemeier. (Eds.), The present of the future (pp. 79-90). diaphanes.

Owens, J. (2019). Post-authenticity and the ironic truths of meme culture. In D. Bristow \& A. Bown, (Eds.), Post memes: Seizing the memes of production (pp. 77-113). Punctum Books.

Respini, E. (Ed.). (2018). The age of the Internet: 1989 to today. The Institute of Contemporary Art/Boston, Yale University Press.

Ross, D. (2015). Touch/Screen. La Deleuziana-Online Journal of Philosophy. N.2 (online).

Rubinstein, D., \& Sluis, K. (2008). A life more photographic. Photographies, $1(1), 9-28$.

Serres, M. (1995). Natural contract (E. MacArthur \& W. Paulson, Trans.). University of Michigan Press.

Smith, P., \& Lefley, C. (2016). Rethinking photography: Histories, theories and education. Routledge.

Stiegler, B. (1998). Technics and time: The fault of Epimetheus (R. Beardsworth \& G. Collins, Eds.). Stanford University Press. 
Stiegler, B. (2010a). Taking care of youth and the generations (S. Barker, Trans.). Stanford University Press.

Stiegler, B. (2010b). For a new critique of political economy (D. Ross, Trans.). Polity Press.

Stiegler, B. (2014). Symbolic misery: The byperindustrial epoch (Vol. 1; B. Norman, Trans.). Polity Press.

Stiegler, B. (2015). Symbolic misery: The catastrophe of the sensible (Vol. 2). Polity Press.

Stiegler, B. (2018). The Neganthropocene (D. Ross, Ed. \& Trans.). Open Humanities Press.

Sundén, J. (2003). Material virtualities: Approaching online textual embodiment. Peter Lang.

Tomkins, C. (2014, March 17). Experimental people: The exuberant world of a video-art visionary. The New Yorker. https://www.newyorker.com/magazine/ 2014/03/24/experimental-people.

Vignola, P. (2015). Alice beyond the selfies, to be worthy of what happens to her. La Deleuziana-Online Journal of Philosophy. N.2 (online).

Virilio, P. (1986). Speed and politics: An essay on dromology. New York: Semiotext (e).

Virilio, P. (1991). The lost dimension. Semiotext(e).

Virilio, P. (1994). The vision machine. Indiana University Press.

Virilio, P. (1998). Architecture in the age of Its virtual disappearance. In J. Beckmann (Ed.), The virtual dimension: Architecture, representation, and crash culture (pp. 178-187). New York: Princeton Architectural.

Virilio, P. (2000). The information bomb (C. Turner, Trans.). Verso.

Virilio, P. (2005). Desert screen: War at the speed of light. Continuum.

Virilio, P. (2011). A winter's journey: Four conversations with Marianne Brausch (C. Turner, Trans.). Seagull Books.

Watkin, C. (2020). Michel Serres: Figures of thought. Edinburgh University Press.

Wiley, S. B. C., \& Elam, J. (2018). Synthetic subjectivation: Technical media and the composition of posthuman subjects. Subjectivity: International Journal of Critical Psychology, 11(3), 203-227.

Zhang, P. (2013). Media ecology and techno-ethics in Paul Virilio. Explorations in Media Ecology, 12(3\&4), 241-257. 
Open Access This chapter is licensed under the terms of the Creative Commons Attribution 4.0 International License (http://creativecommons.org/licenses/ by $/ 4.0 /$ ), which permits use, sharing, adaptation, distribution and reproduction in any medium or format, as long as you give appropriate credit to the original author(s) and the source, provide a link to the Creative Commons license and indicate if changes were made.

The images or other third party material in this chapter are included in the chapter's Creative Commons license, unless indicated otherwise in a credit line to the material. If material is not included in the chapter's Creative Commons license and your intended use is not permitted by statutory regulation or exceeds the permitted use, you will need to obtain permission directly from the copyright holder.

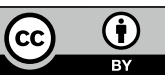

